\title{
The aetiology and prognostic implications of reciprocal electrocardiographic changes in acute myocardial infarction
}

\author{
RENATA KATZ, RONAN M CONROY, KILLIAN ROBINSON, \\ RISTEARD MULCAHY
}

From the Cardiac Department and Department of Preventive Cardiology, St Vincent's Hospital and University College, Dublin, Ireland

SUMMARY The relations between reciprocal ST segment depression in the electrocardiogram and infarct size and 10 year prognosis were studied in 315 patients who survived for at least 28 days after a first anterior or inferior myocardial infarction. ST depression was more common in inferior infarcts $(72 \%)$ than in anterior $(37 \%)$ ones. It occurred more frequently in complicated infarcts and in the presence of considerable ST elevation. Patients experiencing second or third degree heart block were significantly more likely to show reciprocal changes. The rise in peak cardiac enzyme concentration was higher in patients showing ST depression. In patients with ST depression, peak creatine kinase concentration was $46 \%$ higher, aspartate aminotransferase was $39 \%$ higher, and lactate dehydrogenase $29 \%$ higher after correction for site and complications. A discriminant function analysis selected infarct site, peak aspartate aminotransferase, and magnitude of ST elevation as predictors of the occurrence of ST depression. Age, severity, and smoking status did not significantly improve discrimination. Despite larger increases in peak enzyme concentrations patients with ST depression had marginally fewer subsequent episodes of unstable angina or fatal or non-fatal infarction and a marginally lower 10 year death rate. Neither difference was statistically significant. ST depression occurring early in the acute phase of myocardial infarction is likely to be a reflection of electrophysiological changes taking place at the site of the infarct that is manifested in the contralateral surface of the heart. Other causes, however, such as transient ischaemia at the site of the reciprocal changes or extension of the infarct to contiguous areas cannot be excluded in all cases.

In acute myocardial infarction the characteristic elevation of the ST segment of the electrocardiogram is often accompanied by depression of the ST segment remote from the site of the infarction.

The aetiology of these reciprocal ST changes has been the subject of several conflicting reports. Three different explanations have been put forward to account for the phenomenon: (a) that reciprocal changes are an electrophysiological phenomenon in which the observed ST depression is the "rear view" of the classic ST elevation; (b) that ST depression is a product of myocardial necrosis or

Requests for reprints to Professor Risteard Mulcahy, Cardiac Department, St Vincent's Hospital, Elm Park, Dublin 4, Ireland.

Accepted for publication 6 January 1986 ischaemia remote from the site of infarction; (c) that ST depression is a result of the extension of the infarct beyond its stated site.

Most studies to date have been of small numbers of patients and have been confined to in hospital prognosis or short term outcome. In this study we report on the 10 year outcome of 315 patients. We address two questions: (a) Are reciprocal electrocardiogram changes associated with a greater enzymatically estimated infarct size? (b) Do patients with such changes show a long term morbidity or mortality different from patients without them?

\section{Patients and methods}

The patients studied had all been entered into the St Vincent's Hospital Heart Study. This is a long term follow up study of consecutive 28 day survivors of a 
first attack of unstable angina or myocardial infarction. From 1961 to 1975 the study recruited only men under 60 years. When recruitment of a second cohort began in 1978 women were included. For this study we selected patients admitted between March 1970 and December 1975 and between February 1978 and December 1980, inclusive, with a first anterior or inferior infarction. Patients admitted before 1970 were excluded because their hospital charts, which had been transferred to microfilm, frequently lacked complete electrocardiographic records. Patients admitted after 1980 were excluded because of the limited follow up available.

Myocardial infarction was defined as cardiac pain at rest with fresh $Q$ waves in the electrocardiogram or a greater than twofold rise in cardiac enzymes (creatine kinase, lactic dehydrogenase, and aspartate aminotransferase) or both. Only patients with anterior or inferior infarctions were included. Anterolateral infarctions, infarctions at other sites, and infarctions at multiple sites were excluded because there were too few of them for analysis.

Age, sex, and smoking status were recorded. Regular smokers who had given up for three months or more were rated as ex-smokers. Electrocardiograms recorded during the patient's admission were examined. The magnitude of both ST elevation and depression was recorded for each lead of the electrocardiogram. A shift of $1.0 \mathrm{~mm}$ or more in two or more leads was taken as evidence of ST depression or elevation. The leads in which the largest depression and elevation occurred were noted, and the maximum size of both elevation and, where applicable, depression was recorded in $\mathrm{mV}$.

Serial estimations of cardiac enzymes were examined and peak concentrations of creatine kinase, lactic dehydrogenase, and aspartate aminotransferase were recorded. Creatine kinase estimations were not available for patients recruited before 1978 . Of the 20 complications included in our coronary care protocol, four occurred in $15(4.8 \%)$ or more patients. These were: left ventricular failure, ventricular fibrillation, second or third degree heart block, and pericarditis. The analysis was confined to these complications.

Patients were seen at follow up clinic on three occasions in the first year after discharge and annually thereafter. The date of the first non-fatal reinfarction or episode of unstable angina was recorded. Unstable angina was defined as cardiac pain at rest and serial ST-T changes with no rise or a less than twofold rise in cardiac enzyme concentrations. Date and mode of death were recorded for fatal cases and dates on which survivors were last seen were noted.

\section{Results}

The study group comprised 315 patients of whom 25 were women. A hundred and sixty men were admitted between March 1970 and December 1975 inclusive, and 155 patients (of both sexes) were admitted between February 1978 and December 1980 inclusive. The admissions were consecutive apart from 20 patients whose electrocardiographic records were incomplete. Twenty two patients with infarctions at sites other than anterior or inferior ones or at multiple sites were admitted during the study period but these patients were excluded from the analysis. There were $221(70 \cdot 2 \%)$ current cigarette smokers in the group; $29(9.2 \%)$ had never smoked.

Table 1 shows the relation between ST depression and site of infarction. Reciprocal changes occurred in $71.9 \%$ of inferior infarcts and $37.2 \%$ of anterior infarctions $(p<0.0001)$. Complications occurred in 44.6\% of anterior and $53.9 \%$ of inferior infarctions. This difference is not statistically significant. ST depression occurred in $63.5 \%$ of complicated and $47.8 \%$ of uncomplicated infarctions $(p=0.007)$.

Table 2 shows the relation between reciprocal changes and in hospital complications. Patients experiencing second or third degree heart block were significantly more likely to have ST depression. Fourteen of 15 patients experiencing second degree block had inferior infarcts and 13 of them

Table 1 Relation of reciprocal ST depression to site and severity of infarction

\begin{tabular}{|c|c|c|c|c|}
\hline & \multirow[t]{2}{*}{ Total } & \multicolumn{3}{|l|}{$S T$ depression } \\
\hline & & Present & Absent & $p^{\star}$ \\
\hline $\begin{array}{l}\text { All cases } \\
\text { Site: }\end{array}$ & 315 & $175(55 \cdot 6 \%)$ & $140(44 \cdot 4 \%)$ & \\
\hline $\begin{array}{l}\text { Site: } \\
\text { Anterior } \\
\text { Inferior }\end{array}$ & $\begin{array}{l}148(47.0 \%) \\
167(53.0 \%)\end{array}$ & $\begin{array}{r}55(37.2 \%) \\
120(71.9 \%)\end{array}$ & $\begin{array}{l}93(62 \cdot 8 \%) \\
47(28 \cdot 1 \%)\end{array}$ & $<0.0001$ \\
\hline $\begin{array}{l}\text { Severity: } \\
\text { Complicated } \\
\text { Uncomplicated }\end{array}$ & $\begin{array}{l}156(49.5 \%) \\
159(50.5 \%)\end{array}$ & $\begin{array}{l}99(63 \cdot 5 \%) \\
76(47 \cdot 8 \%)\end{array}$ & $\begin{array}{l}57(36.5 \%) \\
83(52.2 \%)\end{array}$ & 0.007 \\
\hline
\end{tabular}

\#Significance levels based on $\chi^{2}$ test. 
Table 2 Relation of reciprocal ST depression to complications

\begin{tabular}{|c|c|c|c|c|}
\hline & \multirow[t]{2}{*}{ Total } & \multicolumn{3}{|l|}{$S T$ depression } \\
\hline & & Present & Absent & $p$ \\
\hline $\begin{array}{l}\text { All cases } \\
\text { Left ventricular failure } \\
\text { Ventricular fibrillation } \\
\text { Second degree heart block } \\
\text { Third degree heart block } \\
\text { Pericarditis } \\
\text { Ventricular extrasystoles }\end{array}$ & $\begin{array}{l}315(100 \%) \\
63(20.0 \%) \\
28(8.9 \%) \\
15(4.8 \%) \\
14(4.4 \%) \\
36(11.4 \%) \\
33(10.5 \%)\end{array}$ & $\begin{array}{l}175(100 \%) \\
41(23.4 \%) \\
18(10 \cdot 3 \%) \\
14(8 \cdot 0 \%) \\
12(6 \cdot 9 \%) \\
21(12 \cdot 0 \%) \\
16(9 \cdot 1 \%)\end{array}$ & $\begin{array}{c}140(100 \%) \\
22(15 \cdot 7 \%) \\
10(7 \cdot 1 \%) \\
1(0.7 \%) \\
2(1 \cdot 4 \%) \\
15(10 \cdot 7 \%) \\
17(12 \cdot 1 \%)\end{array}$ & $\begin{array}{l}\text { NS } \\
\text { NS } \\
0.006 \\
0.041 \\
\text { NS } \\
\text { NS }\end{array}$ \\
\hline
\end{tabular}

Table 3 Relation of reciprocal changes to mean peak cardiac enzyme increase

\begin{tabular}{|c|c|c|c|}
\hline & $C K(I U / l)$ & $A S T(I U / l)$ & $L D H(I U / l)$ \\
\hline $\begin{array}{l}\text { Number of cases } \\
\text { Mean: }{ }^{\star}\end{array}$ & 130 & 291 & 292 \\
\hline $\begin{array}{l}\text { ST depression } \\
\text { No ST depression } \\
\text { Significance of F }\end{array}$ & $\begin{array}{l}1393 \\
956 \\
p=0.002\end{array}$ & $\begin{array}{l}231 \\
166 \\
p<0.001\end{array}$ & $\begin{array}{l}1244 \\
966 \\
\mathrm{p}<0.001\end{array}$ \\
\hline
\end{tabular}

* Means are adjusted for site and severity.

Significance levels based on ANOVA with ST depression, site (anterior or inferior myocardial infarction), and severity as three orthogonal factors.

CK, creatine kinase; AST, aspartate aminotransferase; LDH, lactic dehydrogenase.

Table 4 Factors discriminating between patients with reciprocal changes and patients without ${ }^{\star}$

\begin{tabular}{lll}
\hline Factor & $\begin{array}{l}\text { Percentage of } \\
\text { variance } \\
\text { explained }\end{array}$ & $\begin{array}{l}\text { Standardised } \\
\text { discriminant } \\
\text { coefficient }\end{array}$ \\
\hline Presence of IMI & $11.9 \%$ & 0.8081 \\
Maximum AST rise & $\mathbf{7 . 6 \%}$ & 0.4814 \\
Maximum ST elevation & $3.4 \%$ & 0.4596 \\
Total \% explained & $22.9 \%$ & \\
\hline
\end{tabular}

^Based on discriminant function analysis.

Factors not selected: age, severity, smoking status.

IMI, inferior myocardial infarction; AST, aspartate aminotransferase. showed ST depression. Ten of 14 patients with third degree block had inferior infarcts and all but one showed ST depression.

Table 3 shows the relation between reciprocal changes and infarct size as estimated by peak enzyme rise. We used an analysis of variance with three orthogonal factors: presence of reciprocal changes, topography, and severity. Mean enzyme rise was significantly higher in patients showing reciprocal changes. When corrected for topography and presence of complications peak creatine kinase was $45.7 \%$ higher $(p=0.002)$, aspartate aminotransferase was $39.2 \%$ higher $(p<0.001)$, and lactate dehydrogenase $27.8 \%$ higher $(p<0.001)$ in patients with ST depression than in those without. Complicated infarctions showed a significantly higher peak in all three enzyme concentrations independently of topography and presence of reciprocal changes. Site of infarction was not related to peak enzyme values independently of ST depression or severity.

We performed a discriminant function analysis to assess the relative value of size and site of infarction, age, presence of complications, and smoking status in predicting the occurrence of reciprocal changes. This is a statistical technique which selects the variables which discriminate best between two or more groups. We used a stepwise method in which variables are selected one at a time and selection is

Table 5 Reciprocal ST depression and 10 year prognosis

\begin{tabular}{|c|c|c|c|}
\hline & \multicolumn{2}{|l|}{$S T$ depression } & \multirow[t]{2}{*}{$p$} \\
\hline & Present & Absent & \\
\hline \multirow{3}{*}{$\begin{array}{l}\text { Mortality (all causes): } \\
5 \text { year (SE) } \\
10 \text { year (SE) } \\
\text { Ratio of observed to expected deaths: } \\
\text { CHD mortality: } \\
5 \text { year (SE) } \\
10 \text { year (SE) } \\
\text { Ratio of observed to expected CHD deaths: } \\
\text { Fresh acute CHD rate: } \\
5 \text { year (SE) } \\
10 \text { year (SE) } \\
\text { Ratio of observed to expected events: }\end{array}$} & $\begin{array}{l}18 \cdot 8 \%(3 \cdot 2 \%) \\
32 \cdot 3 \%(4 \cdot 7 \%) \\
84 \cdot 2 \%\end{array}$ & $\begin{array}{l}22 \cdot 7 \%(3.7 \%) \\
46.3 \%(5.6 \%) \\
119.0 \%\end{array}$ & 0.098 \\
\hline & $\begin{array}{l}15 \cdot 3 \%(3.0 \%) \\
26 \cdot 2 \%(4.3 \%) \\
93.6 \%\end{array}$ & $\begin{array}{l}16.1 \%(3.2 \%) \\
31.8 \%(6.7 \%) \\
107.9 \%\end{array}$ & 0.558 \\
\hline & $\begin{array}{l}20.0 \%(3.3 \%) \\
35.7 \%(4.9 \%) \\
87.6 \%\end{array}$ & $\begin{array}{l}24.2 \%(4 \cdot 1 \%) \\
46.1 \%(7.0 \%) \\
116.5 \%\end{array}$ & $0 \cdot 162$ \\
\hline
\end{tabular}

Significance levels based on logrank test. Rates and significances corrected for site and severity of infarction. CHD, coronary heart disease. 
stopped when no other variable significantly increases the correlation between presence of reciprocal changes and the group of predictor variables. Three variables were selected (Table 4): site of infarction, which accounted for $11.9 \%$ of variance; peak aspartate aminotransferase, which added another $7.6 \%$ to the percentage of variance explained; and maximum size of ST depression, which added another $3.4 \%$. Severity, age, and smoking status did not significantly increase the correlation further.

Table 5 shows the relation between reciprocal changes and 10 year outcome. When corrected for topography and severity there was a $35.7 \%$ rate of fresh acute coronary events in the group showing ST depression and a $46.1 \%$ rate in those without $(p=0 \cdot 162)$. Patients with reciprocal changes had a $32.3 \% 10$ year death rate (Table 5 ), compared with $46.3 \%$ in patients without $(p=0.098)$. There was no difference between the groups in 10 year mortality rate for coronary heart disease.

\section{Discussion}

The current interest in reciprocal ST depression in patients with myocardial infarction has yielded several findings which are difficult to reconcile and which have led to widely differing conclusions. Some workers, using various invasive and noninvasive investigations, have concluded that reciprocal changes are not a measure of contiguous or remote ischaemia but reflect an electrical artefact associated with a current of injury at the infarct site. $^{1-7}$ Others believe that the reciprocal changes are associated with an extension of the infarct to contiguous areas, ${ }^{8-12}$ whereas others conclude that the changes are evidence of ischaemia in the reciprocal area of the myocardium remote from the infarct site. ${ }^{91113-16}$

There is some disagreement about the implications of reciprocal changes in relation to immediate and later morbidity and mortality. Nearly all workers who address the subject report a higher frequency of immediate complications in patients when such changes are present. ${ }^{8-12}$

Contrary to what might be expected in view of their greater infarct size, our patients with ST depression did not have a worse 10 year prognosis than those without ST depression. Among the few reports on long term outcome, Wasserman et al, ${ }^{7}$ like ourselves, did not find an adverse effect while Hlatky et al did find a significantly higher long term mortality. ${ }^{8}$ The higher mortality noted by Hlatky et $a l$ in patients with reciprocal ST changes might more reasonably have been expected.

The apparently contradictory findings of various researchers have so far failed to elucidate the nature and implications of reciprocal ST depression. The results which we have presented clarify some of these problems while raising issues for future research. In common with other studies we found that patients with greater ST elevation were more likely to exhibit reciprocal depression. We can also confirm the observation of Goldberg et al that patients with ST depression have significantly higher peak cardiac enzyme concentrations. ${ }^{9}$ No other study, to our knowledge, has attempted to characterise the interrelation of several factors in predicting the occurrence of ST depression. In the patients we studied reciprocal changes were more common in inferior infarction and became more likely with both increasing infarct size and increasing magnitude of ST elevation.

It is important to distinguish between the transient reciprocal changes which occur early in the course of the infarction and resolve within $\mathbf{4 8}$ hours and persistent ST depression. This necessity is highlighted by the study of Gelman and Saltups who divided patients who displayed reciprocal changes into those whose ST depression resolved within 48 hours and those in whom the changes persisted. ${ }^{17}$ The latter group showed a higher incidence of complications whereas the former showed a course similar to patients without reciprocal changes. Because we examined electrocardiogram records retrospectively we could not accurately assess the duration of reciprocal changes. As a result we have not been able to observe this distinction, and this limitation must be borne in mind.

The clear relation found between reciprocal changes and both infarct size and magnitude of ST elevation provides support for the view that reciprocal depression is an electrophysiological phenomenon reflecting changes at the infarct site, since it is most frequently observed in infarctions in which ST elevation is most pronounced. The frequency with which it occurs, particularly in inferior infarctions, argues against necrosis or ischaemia remote from the site of the main infarction, as does the absence of fresh $Q$ waves in the reciprocal area. The reperfusional experiments of Little et al also support this hypothesis. ${ }^{5}$ Other possible mechanisms include transient metabolic or hydraulic effects, or loss of compliance in the reciprocal area simulating an early subendocardial infarction.

The greater frequency of reciprocal changes in inferior infarction has not yet been adequately explained although it may simply be a reflection of the greater number of anterior leads available in the standard electrocardiogram.

Extension of the infarction to contiguous areas such as the posterolateral and inferolateral areas of 
the left ventricle or to the right ventricle in inferior infarction is a reflection of the size of infarct. Several studies support the view that such extension into contiguous areas is more frequent in the presence of reciprocal changes. ${ }^{813-15}$

Because of the current diversity of findings and views on the subject further research is clearly necessary. Future studies should be prospective and should distinguish between transient and persistent ST depression. Both anterior and inferior infarcts should be included, using appropriate radionuclide and angiographic studies of myocardial infarction and perfusion. Finally, further long term follow up studies are needed to clarify the conflicting reports on the relation between reciprocal changes and subsequent morbidity and mortality.

The present study is a retrospective one specifically designed to examine long term morbidity and mortality. Because it is confined to 28 day survivors, it does not address issues concerning the relation of reciprocal changes to other factors and to outcome in the immediate post-infarction period. A substantial number of recent reports have studied this latter area, and they support our findings that reciprocal changes are positively related to size of infarct and to the frequency of complications during the acute phase. For this reason the immediate mortality of the patients with reciprocal changes in our study population may have been higher than that in those without ST depression. From the results presented, however, we can find no effect of reciprocal changes on prognosis, provided that the patient survives the initial 28 days after the infarction.

We thank Dr Ian Graham of the Meath and Adelaide Hospitals for his helpful suggestions, and the Computer Centre of University College Dublin for computing and word processing facilities.

\section{References}

1 Croft CH, Woodward W, Nicod P, et al. Clinical implications of anterior ST segment depression in patients with acute mycardial infarction. Am $\mathcal{F}$ Cardiol 1982; 50: 428-36.

2 Rude RE, Croft CH, Willerson JT. "Reciprocal" anterior ST depression early in the course of transmural inferior myocardial infarction: an ECG finding of uncertain clinical significance. Int $\mathcal{F}$ Cardiol 1983; 4: 80-5.

3 Cohen M, Blanke H, Karsh KR, Holt J, Rentrop P. Implications of precordial ST segment depression during acute inferior myocardial infarction. Arteriographic and ventriculographic correlations during the acute phase. Br Heart F 1984; 52: 497-501.

4 Mukharji J, Murray S, Lewis SE, et al. Is anterior ST depression with acute transmural inferior infarction due to posterior infarction? A vectorcardiographic and scintigraphic study. F Am Coll Cardiol 1984; 4: 28-34.

5 Little WC, Rogers EW, Sodums MT. Mechanism of anterior ST depression during acute inferior myocardial infarction. Observations during coronary thrombolysis. Ann Intern Med 1984; 100: 226-9.

6 Ferguson DW, Pandian N, Kioschos JM, Marcus ML, White CW. Angiographic evidence that reciprocal ST segment depression during acute myocardial infarction does not indicate remote ischaemia: analysis of 23 patients. Am $\mathcal{F}$ Cardiol 1984; 53: 55-62.

7 Wasserman AG, Ross AM, Bogarty D, Richardson DW, Hutchinson RG, Rios JC. Anterior ST segment depression during acute inferior myocardial infarction: evidence for the reciprocal change theory. Am Heart $\mathcal{f}$ 1983; 106: 516-20.

8 Hlatky MA, Califf RM, Lee KL, Pryor DB, Wagner GS, Rosati RA. Prognostic significance of precordial ST-segment depression during inferior acute myocardial infarction. Am $\mathcal{f}$ Cardiol 1985; 55: 325-9.

9 Goldberg HL, Borer JS, Jacobstein JG, Kluger J, Scheidt SS, Alonso DR. Anterior ST segment depression in acute inferior myocardial infarction: indicator of posterolateral infarction. Am $f$ Cardiol 1981; 48: 1009-15.

10 Boden WE, Bough EW, Korr KS, Russo OJ, Gandsman EJ, Shulman RS. Inferoseptal myocardial infarction: another cause of precordial ST-segment depression in transmural inferior wall myocardial infarction? Am $\mathcal{F}$ Cardiol 1984; 54: 1216-23.

11 Haraphongse $M$, Tanomsup S, Jugdutt BI. Inferior ST segment depression during acute inferior myocardial infarction: clinical and angiographic correlations. $\mathfrak{f} \mathrm{Am}$ Coll Cardiol 1984; 4: 467-76.

12 Akhras F, Upward J, Jackson G. Reciprocal changes in ST segment in acute myocardial infarction: correlation with findings on exercise electrocardiography and coronary angiology. $\mathrm{Br} \mathrm{Med}$ f 1985; 290: 1931-4.

13 Salcedo JR, Baird MG, Chambers RJ, Beanlands DS. Significance of reciprocal ST segment depression in anterior precordial leads in acute myocardial infarction: concomitant left anterior descending coronary artery disease? Am $\mathcal{f}$ Cardiol 1981; 48: 1003-8.

14 Jenings K, Reid DS, Julian DG. "Reciprocal" depression of the ST segment in acute myocardial infarction. Br Med F 1983; 287: 634-7.

15 Shah PK, Berman DS, Swan HJC. Precordial ST segment depression in acute inferior myocardial infarction: innocent bystander or high risk indicator? Int $\mathscr{f}$ Cardiol 1983; 4: 75-80.

16 Carelli M, Ceci V, Di Marcotullio G, Citone C, Tubaro M, Milazzotto F. Prognosis in inferior myocardial infarction. Lancet 1984; i: 172-3.

17 Gelman JS, Saltups A. Precordial ST segment depression in patients with inferior myocardial infarction: clinical implications. $\mathrm{Br}$ Heart $\mathcal{F}$ 1982; 48: 560-5. 